\title{
Variability of breast sucking, associated milk transfer and the duration of lactational amenorrhoea
}

\author{
C. R. Prieto ${ }^{1}$, H. Cardenas ${ }^{2}$ and H. B. Croxatto ${ }^{3}$ \\ ${ }^{1}$ Instituto Chileno de Medicina Reproductiva, José Ramón Gutiérrez 2905, Depto 3, Correo 22, Casilla 96, Santiago, Chile; \\ ${ }^{2}$ Facultad de Química y Biología, Universidad de Santiago de Chile, Casilla 40, Correo 33, Santiago, Chile; and \\ ${ }^{3}$ Unidad de Reproducción y Desarrollo, Pontificia Universidad Católica de Chile, Alameda 340, Casilla 114-D, Santiago, Chile
}

Quantitative relationships between physical parameters of sucking, milk transfer and the duration of amenorrhoea were examined in normal mother-baby pairs under exclusive breastfeeding. Sucking pressures were recorded twice on the second and once on the fifth month after birth, during complete breastfeeding episodes, by means of a catheter attached to the nipple and connected to a pressure transducer, the signals of which were analysed by computer. Babies were weighed before and after each sucking episode to estimate milk transfer. In the first nursing episode after noon, 2-month-old babies sucked from 140 to $>800$ times during 4-15 min from the first breast, obtaining from 20 to $>100 \mathrm{~g}$ milk. The physical parameters of sucking and milk transfer exhibited high inter-individual but low intra-individual variabilities. There were significant differences in the physical parameters of sucking and milk transfer efficiency between first and second breast and between the second and fifth months after birth. Milk transfer efficiency was inversely correlated with time occupied by non-sucking pauses $\geq 1.5 \mathrm{~s}$, and was directly correlated with mean intersuck intervals in the first breast and with duration of the sucking episode, number of sucks, mean pressure and area under the pressure curve in the second breast. There was no correlation between the physical parameters of sucking and duration of lactational amenorrhoea $(n=62)$. However, significantly more mothers had amenorrhoea lasting $>180$ days among those whose babies spent a longer proportion of the nursing episode in non-sucking pauses $\geq 1.5 \mathrm{~s}$. This finding indicates that sensory stimulation of the nipple produced during a nursing episode by stimuli other than sucking itself may have an important role in sustaining lactational amenorrhoea. It is concluded that nursing episodes have a complex structure that allows the development of a breastfeeding phenotype in each motherbaby pair, exhibiting important inter-individual variability. The present analysis does not support the contention that this source of variability accounts for the variability in the duration of lactational amenorrhoea.

\section{Introduction}

Breast sucking by human babies fulfils their nutritional needs (Lucas et al.,1979; Bowen-Jones et al., 1982; Woolridge et al., 1982a,b) and acts as a sensory stimulus that triggers acute maternal neuroendocrine responses (Dawood et al., 1981; McNeilly et al., 1983; Johnston and Amico, 1986; UvnäsMoberg et al., 1990). It also provides the primary stimulus responsible for sustaining the ovarian suppression that keeps the mother in amenorrhoea.

Several studies have demonstrated that the longer the duration of lactation, the higher the frequency of sucking episodes in $24 \mathrm{~h}$, and that the later the introduction of food

Received 23 March 1998. supplements, the more prolonged is lactational amenorrhoea (Howie et al., 1981, 1982a,b; Ojofeitimi, 1982; Díaz et al., 1988; Díaz, 1989; Morán et al., 1994). Nevertheless, high interindividual variability within groups of the same population exhibiting the same breastfeeding pattern is still observed. Previous studies at our clinic established that the percentiles 25 and 75 for the duration of amenorrhoea in a homogeneous group of women during exclusive breastfeeding were 2.9 and 8.3 months, respectively (Díaz et al., 1988). This variability was attributed to inter-individual differences in the way babies suck their mothers breast (Díaz et al., 1988) as well as to inter-individual differences in the responsiveness of the mothers to the sucking sensory stimulus but neither of these hypothesis has been proven (Díaz et al., 1991). In the present study, some physical parameters of sucking 
and its associated milk transfer in a large group of mother-baby pairs were measured using methods established in a previous study (Prieto et al., 1996) to assess the interindividual variability in the way babies suck their mother's breast. Furthermore, by repeating these measurements in the same babies at the same age, the intra-individual variability was also assessed. A third measurement carried out 3 months later, in another subgroup, permitted the assessment of the variation related to time after birth. This study was designed to investigate possible correlations between the physical parameters of sucking and the duration of lactational amenorrhoea in a homogeneous group of mother-baby pairs.

\section{Materials and Methods}

Nursing episodes in which measurements were carried out are referred to as recording sessions. A sucking episode was defined as the entire period in which the baby is attached continuously to one nipple until detachment is initiated by the baby or the mother. A nursing episode is the entire period of sucking, whether this is from a single or both breasts, provided it is recognized by the mother as her usual breastfeeding practice. In the few cases in which the usual practice was to suck from a single breast, the nursing episode comprised a single sucking episode. When both breasts were sucked in a nursing episode, they were noted as first and second breast for analysis and reporting. Mothers at our clinic are advised to alternate the first breast from one nursing episode to the next but they do not always follow this advice. At every recording session, the mother was asked to start with either the right or left breast as she would have done naturally and, at 2 months after birth, the choice of the first breast was clearly made by the mother. In spite of this, on almost $60 \%$ of occasions the baby was put first to the left breast.

The measurements done at each recording session included the sucking pressure during the entire episode and the weight of the baby immediately before and after each sucking episode. Breastfeeding was designated as exclusive for the period it was the only source of nutrients and water for the baby. For calculating the total duration of breastfeeding, weaning was considered to have occurred in the first week in which the average number of breastfeeding episodes per day was fewer than one.

\section{Subjects}

Ninety-nine mother-baby pairs were recruited at the family planning clinic of the Instituto Chileno de Medicina Reproductiva. The protocol was approved by the Ethics Committee of the institution and informed consent in writing was obtained from the mothers in each case. All babies were exclusively breastfed and were of normal growth at the time of the recording sessions. All motherbaby pairs participated in a first recording session during the second month after birth and 20 of these pairs participated in a second recording session within the same month. At the fifth month after birth, 21 of the 99 pairs, who were still exclusively breastfeeding, participated in another session. This was the second session for nine of these, and the third session for 12 of them but here they are referred to as a single group called third session for simplicity. The ages of the babies at the first, second and third sessions were $44 \pm 3,48 \pm$ 2 and $153 \pm 2$ days, respectively (values are mean \pm SD unless otherwise stated). The body weights of the babies at each of these sessions were $4827 \pm 489,4859 \pm 321$ and $7355 \pm 730 \mathrm{~g}$, respectively. The age of the mothers was $25 \pm 4$ years and their body weight was $62 \pm 7 \mathrm{~kg}$. The birth weight of the babies was $3325 \pm 350 \mathrm{~g}$. All babies were singletons, had a normal pregnancy, vaginal term delivery, normal weight at birth and normal postpartum evolution. The parity of the mothers ranged from 1 to 3 , and the proportion of female babies was $53 \%$. The percentile 25 , median and percentile 75 for the number of nursing episodes in $24 \mathrm{~h}$ were 9,11 and 13 , respectively. The same measurements were 2, 3 and 4 for the number of nursing episodes during the night.

\section{Sucking pressure recording}

The convenience of the mothers and the circadian variation of prolactin response to sucking were taken into consideration (Díaz et al., 1989), and so all recordings were made between 12:00 $\mathrm{h}$ and 14:00 $\mathrm{h}$ and had to be $>2 \mathrm{~h}$ but $<4$ $\mathrm{h}$ after the preceding breastfeeding to be included in the analysis of the physical parameters of sucking. The relationship between the total amount of milk supplied during the nursing episode in the first recording session and the mean daily weight gain of each baby during the preceding month was examined to assess how representative this feeding was of daily milk intake.

A silicone rubber tubing was taped over the mother's breast with its tip at the level of the nipple, allowing the baby to suck both simultaneously. The other end was connected to a pressure transducer, the signals of which were digitized and stored in a computer for further analysis (for more details, see Prieto et al., 1996). The digitized recording allowed the straightforward quantitation of several parameters: the mean pressure of each episode $(\mathrm{MeP})$, the maximum sucking pressure (MaP), the area under the curve of the pressure changes (AUC), the total number of sucks per sucking episode (NSu) and the duration of the sucking episode ( $\mathrm{Du}$ ). In addition, the time interval between one suck and the next was determined throughout the sucking episode. Owing to their distribution (Fig. 1), these intervals were stratified in two classes: those lasting $<1.5 \mathrm{~s}$, which have a normal distribution and are referred to as intersuck intervals, and those $\geq 1.5 \mathrm{~s}$, which do not have normal distribution and are, therefore, referred to as pauses. Other authors have used 1.3s (Drewett and Woolridge, 1979; Bowen-Jones et al., 1982) or $2.0 \mathrm{~s}$ (Ashmead et al., 1980) as a cut-off point and have considered these longer intervals as resting periods. For each nursing episode, the pauses were added up to obtain the total pausing time. Since longer episodes allowed for more pausing time, the measurements were standardized, and the duration of the sucking episode was taken as $100 \%$, and the percentage of time occupied by the total pausing time calculated. This proportion was Downloaded from Bioscientifica.com at 04/26/2023 12:03:29PM 


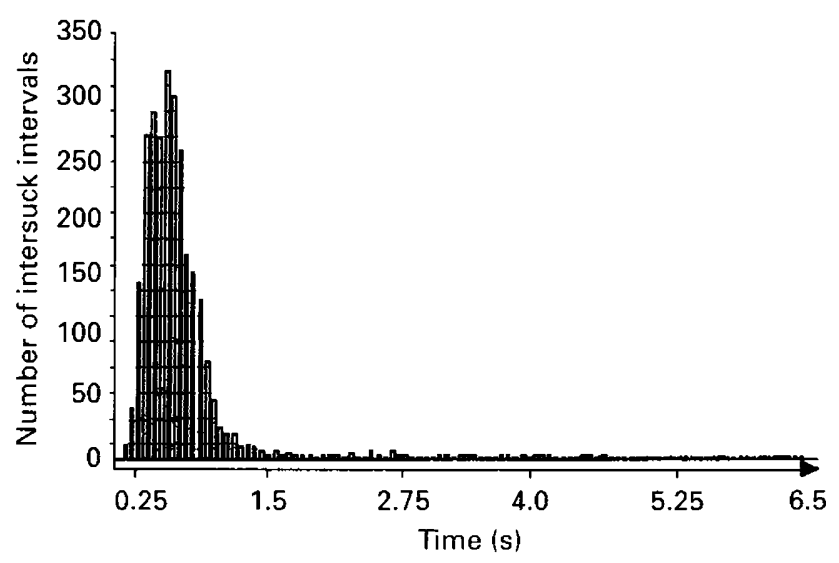

Fig. 1. Distribution of intervals between peak values of negative pressure developed by suckings throughout three complete breastfeeding episodes.

designated the percentage pausing time $(\mathrm{PaT} \%)$. The mean of the intersuck intervals $<1.5 \mathrm{~s}$ (MII) of each sucking episode was also calculated. The babies were weighed on an electronic digital balance accurate to $0.1 \mathrm{~g}$ (Sartorius, model 3862) immediately before and after each sucking episode, and the difference was assumed to correspond to the amount of milk transferred. Milk transfer efficiency (MTE) was expressed as grams of milk transferred: (i) per episode, (ii) per min, (iii) per suck, and (iv) per unit of area under the sucking pressure curve. The values obtained for the MTE per unit of area under the sucking pressure curve were too small and are, therefore, shown in $\mathrm{mg}$ per $\mathrm{mm} \mathrm{Hg} \mathrm{min}{ }^{-1}$. These ratios were used to compare the efficiency of milk transfer between the first and second breast in a nursing episode and from one nursing episode to another.

\section{Duration of lactational amenorrhoea}

The duration of lactational amenorrhoea was defined as the period of time from the day of delivery until the day preceding the onset of the first regular bleeding. A regular bleeding was defined as at least 1 day of menstrual-like bleeding or 3 consecutive days of spotting, followed by a second bleeding within the next 60 days. Sixty-two cases presenting both-breasts nursing episodes in the first recording session and who started to menstruate during the exclusive breastfeeding period and were relying on the lactational amenorrhoea method or on non-hormonal contraceptive methods were included in the analyses of correlations and linear regressions. The anthropometric data of this subgroup did not differ from that of the whole group. The 99 cases who participated in the study were included in the calculation of the mean and SEM of the duration of lactational amenorrhoea.

\section{Statistical analysis}

The description of variables and statistical comparisons was made using the Statistica-Mac Software (rel. 3, StatSoft,
Tulsa, $\mathrm{OK}$ ) and $\mathrm{SAS}^{\oplus}$. Among the physical parameters of sucking and milk transfer efficiency, Du, MaP, NSu, AUC and gram per suck presented a non-normal distribution and, therefore, nonparametric statistics were used for their analysis. Statistical comparisons were done with Wilcoxon or Student's $t$ test for matched paired samples and with Mann-Whitney $U$ or Student's $t$ test for independent samples. Mean and SEM for the duration of exclusive and total breastfeeding and the duration of amenorrhoea were calculated by life table analysis. The amount of milk transferred per episode and per minute was correlated with each of the physical parameters of sucking using Spearman or Pearson $r$ correlations to examine the relationship between sucking and milk transfer. The same tests were used to examine the correlations of each physical parameter with the others. Each of the sucking parameters was correlated with the duration of lactational amenorrhoea using Spearman $r$ correlation to assess the relationship between sucking and the duration of lactational amenorrhoea. The linear regression model was used for multifactorial analysis. Finally, the duration of lactational amenorrhoea was stratified into two categories: 'long' if it lasted $\geq 180$ days and 'short' if it lasted < 180 days (see Díaz et al., 1989). All the physical parameters of sucking were compared between these two categories.

\section{Results}

A nursing episode from a single breast was recorded in 15, 1 and 4 subjects in the first, second and third recording sessions, respectively. All other nursing episodes comprised nursing from both breasts. The single-breast nursing episodes of the second and third recording sessions are not presented in the results because the number of subjects was too small to be analysed as a group. Another eight recordings in which the interval between the recording session and the previous nursing episode was $>4 \mathrm{~h}$ were eliminated from the analysis of the physical parameters of sucking. The groups included in the analysis of physical parameters of sucking and MTE are presented (Tables 1-3).

The correlation between the mean daily weight gain of babies during the preceding month and the amount of milk transferred during the first recording session was statistically significant $(r=0.34, n=99, P<0.01)$. Means \pm SEM for the duration of exclusive and total breastfeeding and the duration of amenorrhoea were $8.5 \pm 0.3,10.9 \pm 0.2$ and $5.6 \pm 0.3$ months, respectively.

A different MTE was observed in single-breast as compared with both-breasts nursing episodes, that is, $\mathrm{g} \mathrm{min}^{-1}$ for single- versus both-breasts nursing in the first recording session were (mean \pm SEM) $9.1 \pm 0.8$ and $5.3 \pm 0.3$, respectively $(P<0.0001)$. For this reason, the results for these two types of nursing episodes are reported separately.

The values of the physical parameters of sucking and MTE are presented (Tables 1 and 2, respectively, for both-breasts nursing episodes; Table 3 for single-breast nursing episodes). There were no significant differences between boys and girls in the physical parameters of sucking or MTE so the data for both sexes were pooled. The statistical comparison between
Downloaded from Bioscientifica.com at $04 / 26 / 2023$ 12:03:29PM 
Table 1. Physical parameters of sucking in both-breasts nursing episodes in human mother-baby pairs

\begin{tabular}{|c|c|c|c|}
\hline $\begin{array}{l}\text { Recording } \\
\text { session }(n)\end{array}$ & Sucking parameter & $\begin{array}{l}\text { First breast } \\
\text { (mean } \pm \text { SEM) }\end{array}$ & $\begin{array}{l}\text { Second breast } \\
(\text { mean } \pm S E M)\end{array}$ \\
\hline First (82) & $\begin{array}{l}\text { Duration }(\mathrm{min}) \\
\text { Mean pressure }(\mathrm{mm} \mathrm{Hg}) \\
\text { Maximum pressure }(\mathrm{mm} \mathrm{Hg}) \\
\text { Mean intersuck interval }<1.55 \mathrm{~s} \\
\text { Number of sucks }(n) \\
\text { Area under the pressure curve }\left(\mathrm{mm} \mathrm{Hg} \mathrm{min}^{-1}\right) \\
\text { Percentage of time spent in pauses } \geq 1.55 \mathrm{~s}\end{array}$ & $\begin{aligned} 8.8 & \pm 0.5 \\
-43 & \pm 2 \\
-135 & \pm 0.7 \\
0.70 & \pm 0.01 \\
435 & \pm 31 \\
22279 & \pm 1249 \\
38 & \pm 2\end{aligned}$ & $\begin{aligned} 8.4 & \pm 0.4 \\
-37 & \pm 2^{*} \\
-136 & \pm 0.8 \\
0.66 & \pm 0.01^{*} \\
394 & \pm 31 \\
19451 & \pm 1608^{*} \\
45 & \pm 2^{*}\end{aligned}$ \\
\hline Second (18) & $\begin{array}{l}\text { Duration }(\mathrm{min}) \\
\text { Mean pressure }(\mathrm{mm} \mathrm{Hg}) \\
\text { Maximum pressure }(\mathrm{mm} \mathrm{Hg}) \\
\text { Mean intersuck interval < } 1.55 \mathrm{~s} \\
\text { Number of sucks }(n) \\
\text { Area under the pressure curve }\left(\mathrm{mm} \mathrm{Hg} \mathrm{min}^{-1}\right) \\
\text { Percentage of time spent in pauses } \geq 1.55 \mathrm{~s}\end{array}$ & $\begin{aligned} 8.2 & \pm 0.8 \\
-55 & \pm 5 \\
-139 & \pm 1.3 \\
0.71 & \pm 0.02 \\
405 & \pm 52 \\
23605 & \pm 3010 \\
32 & \pm 4\end{aligned}$ & $\begin{aligned} 8.4 & \pm 0.8 \\
-36 & \pm 3^{*} \\
-138 & \pm 2.2 \\
0.66 & \pm 0.02^{*} \\
378 & \pm 44 \\
18511 & \pm 2281 \\
47 & \pm 3^{*}\end{aligned}$ \\
\hline Third (15) & $\begin{array}{l}\text { Duration }(\mathrm{min}) \\
\text { Mean pressure }(\mathrm{mm} \mathrm{Hg}) \\
\text { Maximum pressure }(\mathrm{mm} \mathrm{Hg}) \\
\text { Mean intersuck interval }<1.55 \mathrm{~s} \\
\text { Number of sucks }(n) \\
\text { Area under the pressure curve }\left(\mathrm{mm} \mathrm{Hg} \mathrm{min}^{-1}\right) \\
\text { Percentage of time spent in pauses } \geq 1.55 \mathrm{~s}\end{array}$ & $\begin{aligned} 7.9 & \pm 0.6 \\
-47 & \pm 5 \\
-136 & \pm 1.1 \\
0.62 & \pm 0.02 \\
393 & \pm 43 \\
20803 & \pm 2533 \\
41 & \pm 6\end{aligned}$ & $\begin{aligned} 7.5 & \pm 0.6 \\
-45 & \pm 4 \\
-133 & \pm 1.6 \\
0.58 & \pm 0.01^{*} \\
410 & \pm 43 \\
20890 & \pm 2951 \\
43 & \pm 3\end{aligned}$ \\
\hline
\end{tabular}

*Significantly different from corresponding first breast value $(P<0.05$, matched pairs test).

Table 2. Milk transfer efficiency in both-breasts nursing episodes in human mother-baby pairs

\begin{tabular}{|c|c|c|c|}
\hline $\begin{array}{l}\text { Recording } \\
\text { session }(n)\end{array}$ & Milk transfer efficiency & $\begin{array}{c}\text { First breast } \\
(\text { mean } \pm \mathrm{SEM})\end{array}$ & $\begin{array}{l}\text { Second breast } \\
\text { (mean } \pm \text { SEM) }\end{array}$ \\
\hline First (82) & $\begin{array}{l}\text { g per episode } \\
\mathrm{g} \text { min }^{-1} \\
\text { g per suck } \\
\text { mg per unit area under the pressure curve }\end{array}$ & $\begin{aligned} 56 & \pm 2 \\
7.2 & \pm 0.4 \\
0.16 & \pm 0.01 \\
3.3 & \pm 0.2\end{aligned}$ & $\begin{aligned} 34 & \pm 2^{*} \\
4.6 & \pm 0.3^{*} \\
0.11 & \pm 0.01^{*} \\
2.4 & \pm 0.2^{*}\end{aligned}$ \\
\hline Second (18) & $\begin{array}{l}\text { g per episode } \\
\text { g min } 1 \\
\text { g per suck } \\
\text { mg per unit area under the pressure curve }\end{array}$ & $\begin{aligned} 56 & \pm 5 \\
7.8 & \pm 0.9 \\
0.17 & \pm 0.02 \\
3.1 & \pm 0.5\end{aligned}$ & $\begin{aligned} 43 & \pm 5^{*} \\
5.8 & \pm 0.6^{*} \\
0.14 & \pm 0.02 \\
2.9 & \pm 0.4\end{aligned}$ \\
\hline Third (15) & $\begin{array}{l}\text { g per episode } \\
\text { g min }{ }^{-1} \\
\text { g per suck } \\
\text { mg per unit area under the pressure curve }\end{array}$ & $\begin{aligned} 75 & \pm 13 \\
10.5 & \pm 2.1 \\
0.20 & \pm 0.03 \\
4.3 & \pm 0.7\end{aligned}$ & $\begin{aligned} 41 & \pm 5^{*} \\
5.7 & \pm 0.8^{*} \\
0.11 & \pm 0.01^{*} \\
2.2 & \pm 0.3^{*}\end{aligned}$ \\
\hline
\end{tabular}

*Significantly different from corresponding first breast value $(P<0.05$, matched pairs test).

the values of the first and second breast are also presented (Tables 1 and 2). In the first and second recording sessions, MeP, MII and AUC decreased in the second breast, while $\mathrm{PaT} \%$ increased. In the third recording session, only the MII decreased in the second breast.

None of the physical parameters of sucking in single breast episodes (Table 3) differed from the first breast of bothbreasts episodes. In the same comparison, $40 \%$ more milk was transferred and grams per episode and grams per suck were significantly increased in the single breast episodes.
The mean, SD, range and coefficients of variation for each of the variables are presented for the first breast (Table 4). The second breast exhibited the same variability (data not shown). In both breasts, the coefficients of variation for physical parameters of sucking and MTE were $>30 \%$, except for the MaP and MII, both of which presented low coefficients comparable with those of the anthropometric variables of the mothers, which ranged from $3 \%$ for height to $16 \%$ for age. It was deemed necessary to examine correlations among the physical parameters themselves as Downloaded from B10scientifica.com at $04 / 26 / 2023$ 12:03:29PM 
Table 3. Physical parameters of sucking and milk transfer efficiency in 12 single-breast nursing episodes recorded in human mother-baby pairs in the second month after birth

\begin{tabular}{|c|c|}
\hline Variable & $\begin{array}{l}\text { Single breast } \\
(\text { mean } \pm \text { SEM) }\end{array}$ \\
\hline \multicolumn{2}{|l|}{ Sucking } \\
\hline Duration (min) & $8.9 \pm 0.6$ \\
\hline Mean pressure (mm Hg) & $-40 \pm 4$ \\
\hline Maximum pressure $(\mathrm{mm} \mathrm{Hg})$ & $-139 \pm 2$ \\
\hline Mean intersuck interval $<1.55 \mathrm{~s}$ & $0.74 \pm 0.02$ \\
\hline Number of sucks $(n)$ & $400 \pm 33$ \\
\hline 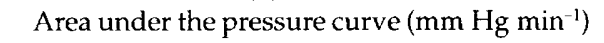 & $22835 \pm 2972$ \\
\hline Percentage of time spent in pauses $\geq 1.55 \mathrm{~s}$ & $40 \pm 4$ \\
\hline \multicolumn{2}{|l|}{ Efficiency } \\
\hline g per episode & $78 \pm 6^{*}$ \\
\hline $\mathrm{g} \min ^{-1}$ & $9.1 \pm 0.8$ \\
\hline g per suck & $0.20 \pm 0.02^{*}$ \\
\hline mg per unit area under the pressure curve & $4.0 \pm 0.5$ \\
\hline
\end{tabular}

\footnotetext{
Values correspond to the first recording session.

*Significantly different from corresponding first breast value of both-breasts episodes recorded in the first session shown in Table 2 $(P<0.05$, independent samples test).
}

well as the intra-individual variation for the interpretation of these variabilities. Some, but not all, parameters had statistically significant correlation with others (Table 5). Several of them were to be expected because of the dependence of some parameters on others. For example, a positive correlation was to be expected of AUC with Du, $\mathrm{MeP}$ and Nsu, and a negative correlation was to be expected with $\mathrm{PaT} \%$. Other correlations, like the negative correlation of MII with Du were not obvious. The MII did not correlate with MeP. Maximum pressure did not correlate with any of the other parameters.

There were no statistically significant differences in the physical parameters of sucking and MTE between the first and second recording session except for $\mathrm{MaP}$ in the first breast, which showed a small $(3.6 \%)$ but statistically significant increase. Nearly half of the mothers used as the first breast in the second or third recording session the same breast they had used first in the first session.

The comparison between the first recording session (second month after birth) and the third recording session (fifth month after birth) showed very few statistically significant differences. The MII decreased by an average of $0.070-0.085 \mathrm{~s}$ in both breasts, indicating an increase in sucking frequency from the second to the fifth month after birth. The average amount of milk transferred per suck and per unit of area under the pressure curve also increased significantly from the second to the fifth month after birth in the first breast by $0.06 \mathrm{~g}$ per suck and $1.9 \mathrm{mg}$ per unit AUC, respectively. More grams of milk per episode and per minute were transferred at the fifth than at the second month after birth, but these differences did not attain statistical significance. The mean number of nursing episodes per $24 \mathrm{~h}$ decreased from 10.5 to 9.6 from the first to the third recording session among the 15 women included in both sessions.

In the first recording session, the grams of milk transferred per episode in the first breast was positively correlated with the MII $(r=0.45, P<0.05)$ and negatively correlated with the
PaT\% $(r=-0.31, P<0.05)$. Grams per minute in the first breast was also correlated with the MII $(r=0.61, P<0.001)$ and $\mathrm{PaT}_{\%}(r=-0.46, P<0.001)$. In the second breast, $g$ per episode was positively correlated $(P<0.05)$ with the $\mathrm{Du}$ $(r=0.26), \mathrm{Nsu}(r=0.38), \mathrm{MeP}(r=0.26)$ and AUC $(r=0.42)$ and negatively correlated $(P<0.05)$ with $\mathrm{PaT} \%(r=-0.32)$. Grams per minute in the second breast was correlated $(P<0.001)$ with the MII $(r=0.43)$ and $\mathrm{PaT} \%(r=-0.43)$.

Correlation coefficients between the physical parameters of sucking and the duration of lactational amenorrhoea were very low, ranging from 0.02 to $0.23 \%$ and none reached statistical significance (data not shown). None of the linear regression coefficients between physical parameters of sucking and the duration of lactational amenorrhoea was statistically significant (data not shown). The comparison of these parameters in short versus long amenorrhoea revealed that the only significant difference was in the distribution of $\mathrm{PaT} \%$ in the two categories of duration of amenorrhoea: $76 \%$ of long periods of amenorrhoea occurred in cases that spent $\geq 50 \%$ of the nursing episode in pausing time, while only $43 \%$ of short periods of amenorrhoea occurred in cases in which PaT\% was $>50 \%(P<0.05$, chi-squared test $)$.

\section{Discussion}

In this study, the physical parameters of sucking and milk transfer were measured in one or more complete nursing episodes during established lactation in mother-baby pairs who were in good health. The babies were growing normally under a regimen of exclusive breastfeeding on demand which was fairly homogeneous across the group studied in terms of the number of day and night feedings. The practice of exclusive breastfeeding during the first 6 months after birth and the duration of lactational amenorrhoea in this group did not differ from other groups studied in this clinic (Díaz et al., 1988, 1989). 
Table 4. Variability of physical parameters of sucking and milk transfer efficiency in the first breast of 82 both-breasts nursing episodes recorded in human mother-baby pairs in the second month after birth

\begin{tabular}{|c|c|c|c|}
\hline \multirow[b]{2}{*}{ Variable } & \multicolumn{3}{|c|}{ First breast } \\
\hline & Mean \pm SD & Range & $\begin{array}{l}\text { Coefficient of } \\
\text { variation }(\%)\end{array}$ \\
\hline \multicolumn{4}{|l|}{ Sucking } \\
\hline Duration (min) & $8.1 \pm 2.2$ & $4-15$ & 27 \\
\hline Mean pressure (mm Hg) & $-43 \pm 16$ & $13-82$ & 37 \\
\hline Maximum pressure $(\mathrm{mm} \mathrm{Hg})$ & $-135 \pm 6$ & $120-150$ & 4 \\
\hline Mean intersuck interval $<1.55 \mathrm{~s}$ & $0.70 \pm 0.07$ & $0.53-0.87$ & 10 \\
\hline Number of sucks $(n)$ & $403 \pm 170$ & $139-865$ & 40 \\
\hline Area under the pressure curve $\left(\mathrm{mm} \mathrm{Hg} \mathrm{min}^{-1}\right)$ & $21312 \pm 10525$ & $6392-56858$ & 49 \\
\hline Percentage of time spent in pauses $\geq 1.55 \mathrm{~s}$ & $38 \pm 16$ & $15-78$ & 42 \\
\hline \multicolumn{4}{|l|}{ Efficiency } \\
\hline g per episode & $58 \pm 22$ & $20-114$ & 38 \\
\hline$g \min ^{-1}$ & $7.7 \pm 3.6$ & $1.7-19.0$ & 47 \\
\hline gper suck & $0.17 \pm 0.08$ & $0.04-0.46$ & 47 \\
\hline mg per unit area under the pressure curve & $3.5 \pm 2.3$ & $0.8-14.9$ & 66 \\
\hline
\end{tabular}

Values correspond to the first recording session.

Table 5. Correlations between the physical parameters of sucking recorded from the first breast in 82 human mother-baby pairs

\begin{tabular}{lccccccc}
\hline & Dut & MeP & MaP & MII & NSu & AUC & PaT\% \\
\hline $\mathrm{Du}$ & 1.00 & & & & & & \\
$\mathrm{MeP}$ & 0.01 & 1.00 & & & & & \\
$\mathrm{MaP}$ & 0.12 & 0.003 & 1.00 & & & & \\
$\mathrm{MII}$ & $-0.56^{*}$ & -0.14 & 0.08 & 1.00 & & & \\
$\mathrm{NSu}$ & $0.59^{*}$ & $0.49^{*}$ & $-0.07^{*}$ & $-0.51^{*}$ & 1.00 & & \\
$\mathrm{AUC}$ & $0.51^{*}$ & $0.82^{*}$ & 0.07 & $-0.34^{*}$ & $0.74^{*}$ & 1.00 & \\
$\mathrm{PaT} \%$ & $0.36^{*}$ & $-0.49^{*}$ & 0.13 & -0.20 & $-0.37^{*}$ & $-0.22^{*}$ & 1.00 \\
\hline
\end{tabular}

Du: duration of sucking episode; MeP: mean pressure: MaP: maximum pressure; MIl: mean of intersuck intervals $<1.5 \mathrm{~s}$; NSu: number of sucks; AUC: area under the pressure curve; $\mathrm{PaT} \%$ : percentage of DU spent in intersuck intervals $\geq 1.5 \mathrm{~s}$. Italicized values correspond to Pearson $r$ and the other values to Spearman $r$. $* P<0.05$.

The main findings of the present study are the high variability among different babies in the way they suck and the rather poor correlation between the physical parameters of sucking and milk transfer efficiency and their lack of correlation with the duration of lactational amenorrhoea.

The values encountered for the physical parameters of sucking did not show major differences from those obtained using other methods. For example, Ashmead (1980) reported an MII of $0.87 \mathrm{~s}$ and a MeP of $-37 \mathrm{~mm} \mathrm{Hg}$ in 3-day-old babies during bottle-feeding. Similarly, the present data for milk transfer coincide with previous data obtained with the same methodology. For example, Woolridge et al. (1982a) found an average ( \pm SEM) milk transfer of $57 \pm 8 \mathrm{~g}$ per episode in the first breast and of $34 \pm 4 \mathrm{~g}$ per episode in the second breast in 26-day-old babies.

The high inter-individual variability observed for most physical parameters of sucking contrasts with their low intraindividual variability, indicating that the inter-individual variability truly represents variation between individuals. The fact that some physical parameters of sucking present fairly good correlation among themselves, while others do not, indicates that they can combine themselves in a vast diversity of patterns. We believe that this feature, in conjunction with the interactive nature of breastfeeding leads to the establishment of a particular 'breast sucking phenotype' for each mother-baby pair. Therefore, we propose that the physical parameters of sucking and the associated milk transfer for each pair have an individuality that is comparable, to some extent, with that of their fingerprints. This concept is supported by the analysis of inter-individual variation done in other studies of human lactation (for example, see Daly et al., 1993; Daly and Hartmann, 1995).

Two parameters, the MaP and MII, had an exceptionally low variability that is surprising, particularly in the case of the MaP. The low variability of the MII is in keeping with that of other rhythmic phenomena, such as heartbeat or breathing, which are controlled by pacemakers or pulse generators and which also exhibit low variability from one individual to another. The developmental acquisition of the 
sucking rhythm reported by Hack et al. (1984) in premature human babies culminates in mean intersuck intervals of $0.7 \pm$ $0.1 \mathrm{~s}$, indistinguishable from those reported in the present study, and indicate that a neural pulse generator may determine the intersuck intervals and their low variability.

The present study also confirms earlier descriptions of the relationship between some physical parameters of sucking and milk transfer. For example, Bowen-Jones et al. (1982) observed that sucking frequency increased as milk flow decreased along the sucking episode. In the present study, larger amounts of milk transferred were associated with lower sucking frequency. In this association, the lower sucking frequency is more likely to be a consequence of the increase in milk flow from the maternal breast since, when the babies suck bottles with holes of different size, the sucking frequency increases in response to a decrease in the nutrient flow (Colley and Creamer, 1958). However, an exception to this rule was found when sucking frequency and MTE in the second and fifth months after birth were compared. Increased MTE was associated with increased sucking frequency in the fifth month after birth. Thus, babies obtained more milk in less time at the fifth month after birth, with a lower $\mathrm{NSu}, \mathrm{MeP}$ and higher $\mathrm{PaT} \%$ and a minimal change in the number of feeds per $24 \mathrm{~h}$.

That the duration of episodes had poor correlation with the amount of milk transferred and that this was significant only for the second breast probably reflects that $89 \%$ of the milk is transferred in the first 4 min (Lucas et al., 1979). Woolridge et al. (1982a) showed that milk transfer from the breast in a single episode is fairly independent of duration of the episode, and strongly depends on the amount of milk stored and the capacity of the breast to eject milk, as well as on intrinsic characteristics of the baby.

The changes in sucking parameters from the first to the second breast were associated with lower MTE in the second breast. In contrast with the first breast, the amount of milk transferred in the second breast seems to depend on the energy invested by the baby, since it was positively correlated with $\mathrm{Du}, \mathrm{MeP}, \mathrm{NSu}$ and $\mathrm{AUC}$, and negatively correlated with $\mathrm{PaT} \%$. These differences were observed in mothers who alternated the first breast as well as in those who had fixed the first breast and, therefore, indicate that the physiology of breastfeeding in the first breast differs from that in the second breast.

The relationships of $\mathrm{PaT} \%$ with milk transfer and with the duration of amenorrhoea are intriguing and perhaps interrelated. The $\mathrm{PaT} \%$ is the only parameter that presented a significant as well as negative correlation with the amount of milk transferred in both breasts. Since $\mathrm{PaT} \%$ is higher when milk transfer is lower, this finding may reflect a non-nutritive function for breastfeeding, for example, the time spent by the baby in providing sensory stimulation to the nipple. This interpretation, although speculative, fits with the higher values of $\mathrm{PaT} \%$ associated with long amenorrhoea.

One of the hypotheses considered was that babies who needed a larger area under the pressure curve or number of sucks to obtain their nutritive quota of milk would cause more sensory stimulation of the nipple and that, therefore, their mothers would have longer amenorrhoea. However, no correlation between those parameters and the duration of lactational amenorrhoea was found. Therefore, duration of lactational amenorrhoea bears no relationship to the physical parameters of sucking measured in a single complete nursing episode. This lack of correlation could result from the nursing episode actually measured being unrepresentative of the nursing episodes over a $24 \mathrm{~h}$ period (Daly and Hartmann, 1995). Nevertheless, the positive and statistically significant correlation between the amount of milk transferred during the first recording session and the mean daily weight gain of the babies in the preceding month indicates that this episode was, in fact, representative of the amount of milk transferred in $24 \mathrm{~h}$.

Taken altogether, the analysis of variability presented implies that a 'breastfeeding phenotype' is established in each mother-baby pair. The finding that the variability in the physical parameters of sucking of the entire sucking episode does not explain the variability in the duration of lactational amenorrhoea seems to be definitive.

The collaboration of midwives and clinic personnel in the recruitment and follow up of volunteers for this study is gratefully acknowledged. The revision of the manuscript and helpful suggestions by A. Van Beek are much appreciated. This study was funded by FONDECYT Project 1960744, UNDP/UNFPA/WHO/ World Bank special Program of Research Development, and Research Training in Human Reproduction, The Rockefeller Foundation Grant $94025 \# 15$ and Local Arrangements Ltd, San Antonio, TX.

\section{References}

Ashmead H, Reilly BM and Lipisitt LP (1980) Neonates heart rate, sucking rhythm, and sucking amplitude as a function of the sweet taste lournal of Experimental Child Psychology $29264-281$

Bowen-Jones A, Thompson C and Drewett RF (1982) Milk flow and sucking rates during breast-feeding Developmental and Medical Child Neurology 24 626-633

Colley JRT and Creamer B (1958) Sucking and swallowing in infants British Medical Journal $2422-423$

Daly SEJ and Hartmann PE (1995) Infant demand and milk supply I. Infant demand and milk production in lactating women Journal of Human Lactation $1121-26$

Daly SEJ, Owens RA and Hartmann PE (1993) The short-term synthesis and infant-regulated removal of milk in lactating women Experimental Physiology 78 209-220

Dawood MY, Khan-Dawood FS, Wahi RS and Fuchs F (1981) Oxytocin release and plasma anterior pituitary and gonadal hormones in women during lactation Journal of Clinical Endocrinology and Metabolism 52 678-683

Díaz S, Rodríguez G, Marshall G, del Pino G, Casado ME, Miranda P, Schiappacasse V and Croxatto HB (1988) Breastfeeding pattern and the duration of lactational amenorrhoea in urban Chilean women Contraception 38 $37-51$

Díaz S (1989) Determinants of lactational amenorrhoea International Journal of Gynecologyand Obstetrics Supplement $183-89$

Díaz S, Serón-Ferré $M$, Cardenas $H$, Schiappacasse $V$, Brandeis $A$ and Croxatto HB (1989) Circadian variation of basal plasma prolactin, prolactin response to suckling, and length of amenorrhoea in nursing women fournal of Clinical Endocrinology and Metabolism 68 946-955

Díaz S, Cardenas H, Brandeis A, Miranda P, Schiappacasse V, Salvatierra AM, Herreros C, Serón-Ferré M and Croxatto HB (1991) Early difference in the endocrine profile of long and short lactational amenorrhoea Journal of Clinical Endocrinologyand Metabolism 72 196-201

Drewett RF and Woolridge M (1979) Sucking patterns of human babies on the breast Early Human Development 3 315-321

Hack M, Eastbrook MM and Robertson SS (1984) Development of sucking rhythm in preterm infants Early Human Development 11 133-140 
Howie PW, McNeilly AS, Houston MJ, Cook A and Boyle H (1981) Effect of supplementary food on suckling patterns and ovarian activity during lactation British Medical Journal 283 757-759

Howie PW, McNeilly AS, Houston MJ, Cook A and Boyle H (1982a) Fertility after childbirth: infant feeding patterns, blood PRL levels and postpartum ovulation Clinical Endocrinology 17 315-322

Howie PW, McNeilly AS, Houston MJ, Cook A and Boyle H (1982b) Fertility after childbirth: postpartum ovulation and menstruation in bottle and breast feeding mothers Clinical Endocrinology 17 323-332

Johnston JM and Amico JA (1986) A prospective longitudinal study of the release of oxytocin and prolactin in response to infant suckling in long term lactation Journal of Clinical Endocrinology and Metabolism 62 653-657

Lucas A, Lucas PJ and Baum JD (1979) Pattern of milk flow in breast-fed infants Lancet 257-58

McNeilly AS, Robinson IC, Houston MJ and Howie PW (1983) Release of oxytocin and prolactin in response to suckling British Medical Journal 286 $257-259$
Morán C, Alcázar LS, Carranza-Lira S, Merino G and Bailón R (1994) Recovery of ovarian function after childbirth, lactation and sexual activity with relation to age of women Contraception 50 401-407

Ojofeitimi EO (1982) Effect of duration and frequency of breastfeeding on postpartum amenorrhoea Pediatrics 69 164-168

Prieto CR, Cardenas H, Salvatierra AM, Boza C, Montes CG and Croxatto HB (1996) Sucking pressure and its relationship to milk transfer during breastfeeding in humans fournal of Reproduction and Fertility 108 69-74

Uvnäs-Moberg K, Widström AM, Werner S, Matthiesen AS and Winberg J (1990) Oxytocin and prolactin levels in breast-feeding women. Correlation with milk yield and duration of breast-feeding Acta Obstetrica and Gynecologica Scandinavica 69 301-306

Woolridge MW, Baum JD and Drewett RF (1982a) Individual patterns of milk intake during breast-feeding Early Human Development 7 265-272

Woolridge MW, How TV, Drewett RF, Rolfe P and Baum JD (1982b) The continuous measurement of milk intake at a feed in breast-fed babies Early Human Development 6 365-373 